\title{
Reviews of Books
}

The Development of the Human Dental Mechanism: the Significance of the Deciduous Teeth: Orthodontia as an Aid to Padiatrics. W. Stanley Wilkinson. (Medical Journal of Australia, 22 nd July I922, No. 4, Vol. cxvii.)

The symmetry of the facial bones is largely dependent on the correct development of the teeth.

The width of the nasal cavities and of the sphenoid bone which accommodates the hypophysis cerebri are both directly influenced by dental development, and by the action of muscles of mastication.

The apices of the bicuspid and molar teeth are on the same level as the floor of the nose, and expansion of any or all of them will result in nasal expansion.

Mal-position of the teeth throws the muscles of mastication out of proper alignment, hence the facial bones to which the muscles are attached are not developed on normal lines. Malformation of the facial bones, resulting in high arched palate and contracted nasal fossæ, cannot be treated satisfactorily without the co-operation of the orthodontist, who is able to expand the palate, and secure a proper apposition of the teeth.

The influence of the deciduous teeth on the development of the bones of the face is described; their injudicious extraction is to be avoided.

Modern methods apply expansion to the roots not the crowns of the teeth, and as the roots are on a level with the floor of the nose the nasal cavity is also widened. The paper is well illustrated.

A. J. Brady.

\section{REVIEWS OF BOOKS}

The Medical Annual: A Year-Book of Treatment and Practitioner's Index for 1922 (fortieth year). Pp. 596. Bristol: JoHN Wright \& Sons, Lrd. London: Simpkin, Marshall, Hamilton, Kent \& Co., Ltd. Price 20 s. net.

Every year finds one more and more dependent on the row of Medical Annuals on one's bookshelves, for information not merely on our special subjects but also on general medical and surgical questions which no self-respecting specialist can afford to forget or ignore. In the present volume $\mathrm{Mr}$ Wright has taken up the work long carried on so well by Dr Watson Williams and Dr Fraser. He has served up a thoroughly good menu, both satisfying and digestible.

Otitis media, acute and chronic, with their complications, receive attention in well-written articles. For cavernous sinus thrombosis, VOL. XXXVII. NO. XI. $5^{8} 3$ 2 N 3 


\section{Reviews of Books}

repeated bleeding from the sigmoid sinus is recommended. This was advocated by Körner many years ago and does not seem to have received the attention it deserved.

Chevalier Jackson condemns high tracheotomy as being a very usual cause of laryngeal stenosis. Attention is drawn to the association of accessory sinus disease with bronchitis and bronchiectasis as well as with chronic bronchorrhœa resembling tuberculosis. Among new points in relation to frontal sinusitis we note Unger's use of india-rubber catheters introduced through the natural orifice on a probe. The vital dilatation effected by india-rubber tubes in the larynx and elsewhere is probably in action here though it is not mentioned as such. In malignant disease of the sinuses Barnes's recommendation of Moure's operation followed by retention of a tube of radium emanation is quoted. The references are numerous and full.

In addition to our own special subjects the Annual deals with almost every possible branch of the healing art in even more than the usual complete manner. In general medical and surgical interest it surpasses itself. We may cite Hey Groves' article on orthopædic surgery and most particularly Langdon Brown's masterly and attractive study of the endocrine glands. Cancer is considered from every point of view, but especially in Thurstan Holland's articles on Radiotherapy. Unusually long articles are devoted to Mental Disease (Stanford Read), modern Psychological Medicine (Hadfield), Skin Diseases (Graham Little), Protein Sensitisation (French), Anæsthetics (Blomfield), and particularly the Surgery of the Thyroid Gland (James Berry). The influence of the tonsils in affording a focus for infections of great variety, is emphasised by many writers as in alopecia areata, exophthalmic goitre and, among other diseases, mononuclear leucocytosis.

The Annual will this year be found more valuable than ever to the practitioner, whether general or special. Jas. DUndas-Grant.

\section{Atti della Clinica Oto-Rino-Laryngoiatrica della $R$. Universita di Roma. GiUSEPPE FARRI, Roma. I 92 I.}

The eighteenth annual volume of the published works of the Royal Oto-laryngological Clinic in Rome for the year 1920 is well up to the standard of its predecessors, and Professor Ferreri is to be congratulated on its quality. It consists of 479 pages of original matter contributed by the members of the clinic, and contains a bibliography of Italian work for the years 1918-19 compiled by Dr Vitto Massei. It is rather invidious to pick out one or two of a series of about twenty articles, but one by Bilancioni is worthy of mention in that it gives a fairly complete resumé on the subject of cholesteatoma of the ear illustrated by 